\title{
АНАИИЗ ЭФФЕКТИВНОСТИ ПРЕПОДАВАНИЯ, ОСВОЕНИЯ УЧЕБНОГО МАТЕРИААА И СИСТЕМНОЕ АДМИНИСТРИРОВАНИЕ ДАННОГО ПРОЦЕССА В ДИСТАНЦИОННОМ ФОРМАТЕ
}

\section{(C) Газимагомадов X.M.}

ФГБОУ ВО «Грозненский государственный нефтяной технический университет

имени академика М. Д. Миллионщзикова», г.Грозный

Дистанционное обучение становится актуальным и популярным в современном обществе. Люди разных специальностей получили возможность учиться дистанционно. Внедрение дистанчионного обучения повлекло за собой потребность разработки и использование дистанционных образовательных информационных технологий. Как и все новые технологии, дистанционное обучение имеет некоторые преимущества и недостатки.

Цель анализа - определить плюсы и минусы дистанционного обучения инженеров-энергетиков. В докладе анализируется процесс преподавания, освоения учебного материала, а также системное администрирование данного процесса.

Ключевые слова: образование будущего, дистанционное образование, дистанционное обучение, педагогика, технические специальности.

Важным аспектом любого анализа является структурное разделение на составляющие тематики и их дробный анализ. Основными участниками дистанционного процесса являются студенты, преподаватели и администраторы учебного процесса [3]. Рассмотрим их на основании опыта в данных сферах деятельности.

Опыт преподавания в дистанционном формате. В качестве аргумента моей статье я обращусь к опыту наблюдения за преподаванием профессорско-преподавательского состава профильной кафедры по подготовке инженеров-энергетиков в дистанционном формате. Преподаватели должны иметь электронный учебно-методический курс (ЭУМК), а также необходимые дистанционные и информационные технологии (персональный компьютер/ноутбук, интернет). 
Дистанционное обучение - это форма получения образования, при которой преподаватель и студент взаимодействуют на расстоянии с помощью дистанционно-информационных технологий. Говоря о дистанционном образовании, сегодня чаще всего имеют в виду обучение с использованием интернет-технологий. Однако технология здесь - это лишь инструмент передачи знаний и организации взаимодействия [1]. Во время дистанционного обучения студент занимается самостоятельно по разработанной программе, просматривает записи онлайн- конференций, вебинаров, решает задачи, консультируется с преподавателем в онлайн-чате и систематично отдает ему на проверку свои работы. Учебный материал представляется в виде электронного формата, а также в видеофайлах. Изучать учебный материал надо самостоятельно.

Дистанционное образование предполагает проведение онлайн-семинаров. Для подготовки к ним студенты изучают заданную тему, подготавливают необходимую информацию. Наиболее эффективны онлайн-беседы группы учащихся и преподавателя: так через дистанционные технологии осуществляется прямая связь одновременно со всеми участниками. Дистанционное обучение также включает сдачу зачетов, экзаменов и лабораторных или практических работ в режиме онлайн: учащийся отвечает на вопросы преподавателя, как правило, для связи используется зум. В некоторых случаях задания по темам могут высылаться по электронной почте. Время, отведенное на отправку ответов, нормируется.

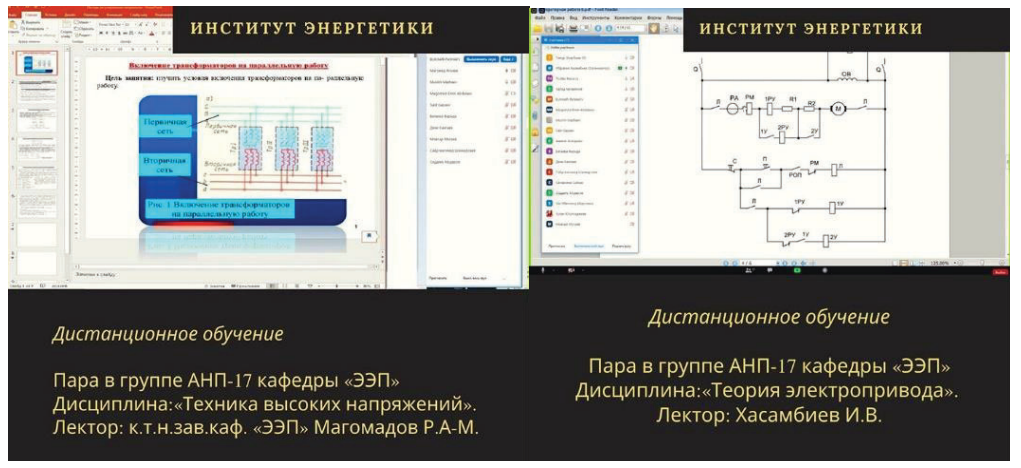

Рис. 1. Скриншоты онлайн-пар с использованием дистанциионых технологий 


\section{Преимущества:}

1. Возможность работать с каждым учеником индивидуально;

2. Автоматизация рутинных процессов;

3. Шанс освоить новые технологии;

4. Более размеренный темп работы;

5. Возможность работать в комфортной обстановке;

6. Актуальность знаний;

7. Доступность учебных материалов.

\section{Недостатки:}

1. Необходимость разбираться в цифровых технологиях;

2. Недостаток личного общения;

3. Необходимость работать с мотивацией учеников;

4. Отсутствие границы между рабочим и свободным временем.

Опыт освоения учебного материала в дистанционном формате. Я как студент кафедры по подготовке инженеров-энергетиков хочу рассказать о своем опыте освоения учебного материала в дистанционном формате. Цифровизация образования подразумевает интеграцию различных информационных технологий, в том числе технологий онлайн-обучения и средств коммуникации с использованием цифровых интерфейсов в единую электронную (цифровую) информационно-образовательную среду [2]. Студенты должны иметь доступ к электронному учебно-методическому курс (ЭУМК), опубликованный в электронной информационно-образовательной среде ВУЗа, а также необходимые дистанционные и информационные технологии (персональный компьютер/ноутбук, интернет). Существует множество трактовок понятия «Электронный курс». Для того чтобы избежать путаницы, предлагаю опираться на следующий признак, сформулированный академиком Российской академии образования, доктором педагогических наук, профессором, Ирэной Веньяминовной Роберт: «Электронное учебное пособие (электронный курс, компьютерный тест) не могут быть сведены к бумажному варианту без потери дидактических свойств». Поэтому: конспекты лекций, презентации, учебники, 
методические пособия, размещенные где бы то, ни было в электронном виде, остаются лишь электронными копиями соответствующих материалов. Электронным курсом все это становится только при условии реализации в ЭУК интерактивного взаимодействия с обучаемым, адаптирующимся к его потребностям, позволяющим реализовывать вариативность образовательных траекторий [5].

Студентов дистанционного формата обучения так же, как и всех остальных учащихся, обучают по строго нормированной учебной программе. Им выдают расписание занятий, логин и пароль для доступа в свой личный кабинет на сайте. В личном кабинете студенты могут находить доступные для них учебные пособия - записи лекций, конспекты, учебники, контрольные и прочие проверочные материалы. Там же им выдаются задания на неделю или на семестр. Все эти материалы могут быть отправлены преподавателем и на электронную почту академической группы, обучающейся в дистанционном формате.

На главной странице в своем личном кабинете студент видит список доступных дисциплин и прочую важную информацию. Изучать дисциплины студент может самостоятельно и в удобном ему порядке по электронным учебникам и различным пособиям, которые есть у него на страничке. К учебникам могут прилагаться также видеолекции. После изучения дисциплины, студент закрепляет полученные знания путем сдачи промежуточных или итоговых тестов. Дисциплины могут предполагать лабораторные, практические и курсовые работы, которые тоже выполняются посредством интернета.

Как и при заочной и очной форме обучения студенты ДО (дистанционного обучения) проходят практику по профилю. Место прохождения практики необходимо искать самостоятельно и по итогам ее прохождения представить преподавателю отчет в электронном виде.

На последнем курсе студент выполняет дипломную работу или проект. Руководство дипломным проектированием, тоже осуществляется дистанционно, что позволяет оперативно исправлять недостатки и замечания руководителя. Обязательно приехать в учебное заведение или к региональному партнёру студенту нужно будет для сдачи государственных экзаменов и защиты дипломной работы. 


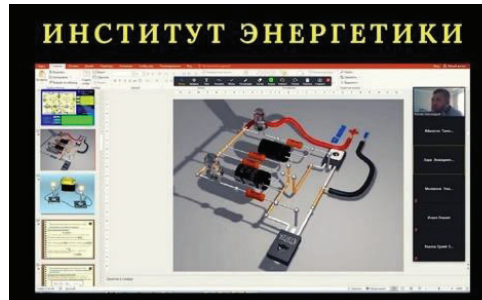

Дистанционное обучение

Пара в группах ЗНГ-16, ЗГИ- 16 . Дисциплина: «Электротехника и электроника».

Преподаватель: Зав. каф. «ЭЭП», к.т.н. Магомадов Рустам А-M.

\section{ИНСТИТУТ ЭНЕРГЕТИКИ}

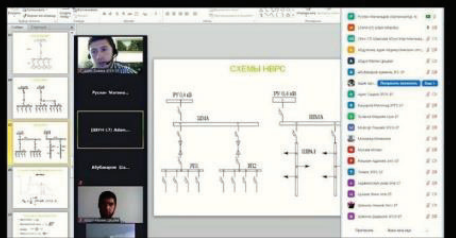

Дистаниионное обучение

Пара в группах 3ГСХ-17, 3ТГВ-17, 3ПСК-17, ЗэУН-17, ЗПГС-17

Дисциплина: «Электроснабжение.

Основы электротехники».

Преподаватель: Магомадов Руслан А-M

Рис. 2. Скриншоты онлайн-пар с использованием дистаничинных технологий

\section{Преимущества:}

1. Самодисциплина;

2. Более размеренный темп работы;

3. Возможность работать в комфортной обстановке;

4. Актуальность знаний;

5. Доступность учебных материалов;

6. Возможность обучаться в любом месте;

7. Стеснительные студенты более активно проявляют себя в онлайн-парах.

8. Дистанционное образование дешевле.

\section{Недостатки:}

1. Необходима сильная мотивация;

2. Недостаток практических знаний;

3. Отсутствие развития коммуникабельности.

\section{Опыт системного администрирования процесса дистан-} ционного обучения. Так как я системный администратор института энергетики, я бы хотел рассказать о своём опыте работы в дистанционном формате. Несмотря на появление и развитие системы федеральных образовательных порталов, многие учебные заведения продолжают накапливать учебно-информационные ресурсы на своих серверах, чтобы обучать студентов с использованием дистанционных технологий. Сети учебных 
заведений называются локальными [4]. Системный администратор должен получить электронный учебно-методический курс (ЭУМК) для дальнейшего опубликования и доступа студентами на сайте ВУЗа/института, а также необходимо иметь дистанционные и информационные технологии (персональный компьютер/ноутбук, интернет).

До начала дистанционного обучения, системный администратор ведет сбор учетных данных виртуальных кабинетов преподавателей для проведения онлайн-пар. В начале процесса дистанционного обучения, системный администратор сопровождает как преподавателей, так и студентов, проводя информационно учебно-вспомогательную работу, в дистанционном формате. Системный администратор в конце каждого рабочего дня высылает конечный сбор отчетов преподавателей о проведении пар директору подразделения. А также ведет отчет о проделанной работе институтом на официальном сайте института и официальном аккаунте в Instagram.
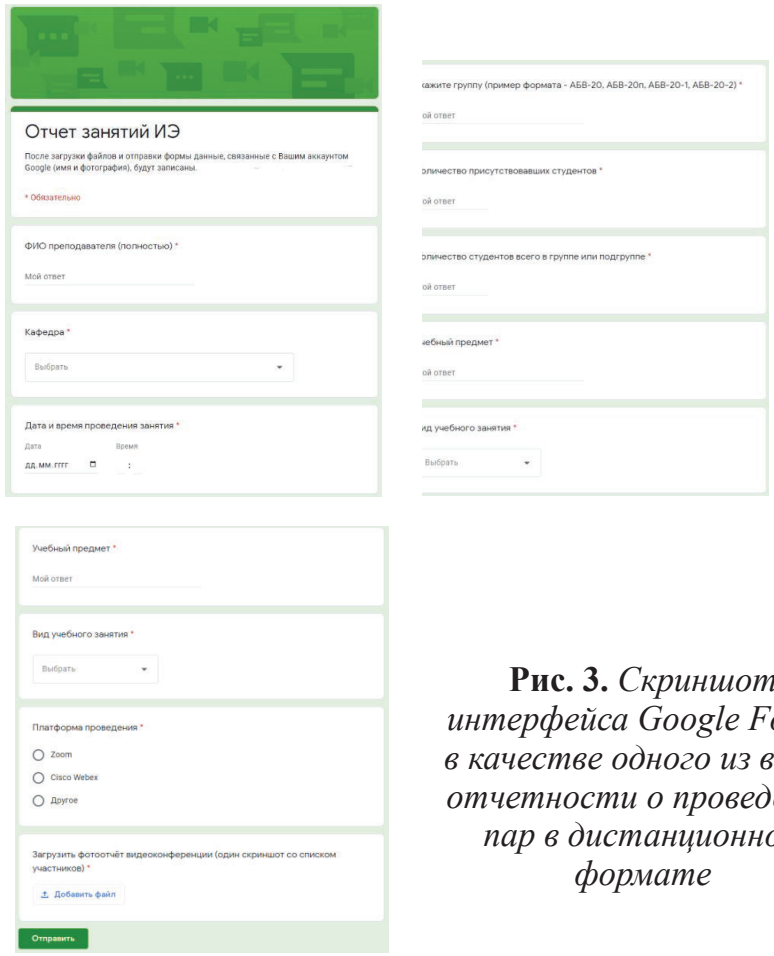

Рис. 3. Скриншот интерфейса Google Forms в качестве одного из видов отчетности о проведении пар в дистанционном формате 


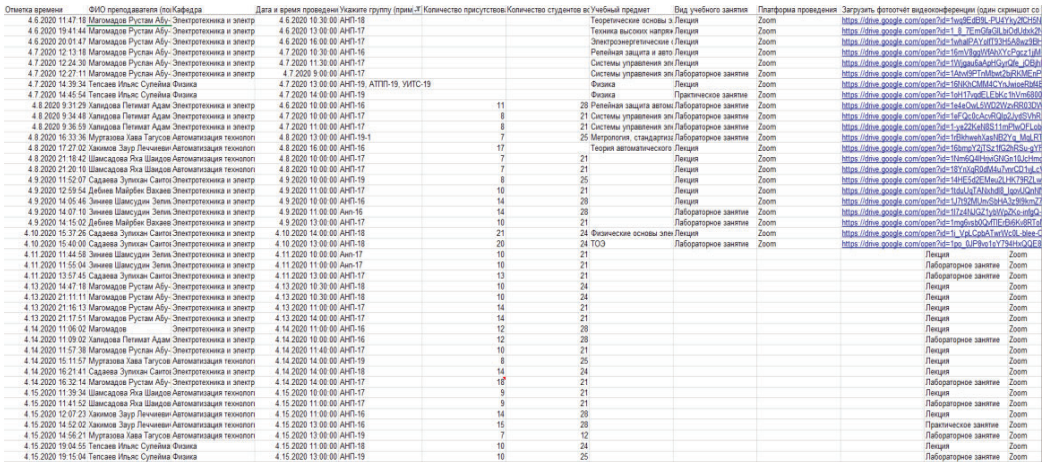

Рис. 4. Скриншот конечной таблищъы отчетности с помощзью дистанционной технологии Google Forms

\section{Преимущества:}

1. Быстрое решение системных проблем;

2. Системный дистанционный доступ к информационнодистанционным технологиям;

3. Автоматизация рутинных процессов;

4. Возможность работать в комфортной обстановке;

5. Шанс освоить новые технологии.

\section{Недостатки:}

1. Отсутствие локального доступа к железу информационно-дистанционных технологий;

2. Отсутствие границы между рабочим и свободным временем.

Bblводы. Как и у всех технологий, у технологий дистанционного обучения есть свои преимущества и недостатки. Дистанционное обучение неизбежно заставит вас сражаться с самым суровым противником - собственной ленью. И если вы к этому поединку не готовы, лучше вовсе не начинайте бой. Однако если вы уверены в своих силах и твердо намерены преподавать и/или учиться, дистанционное образование предложит вам разнообразные возможности для профессионального и личностного совершенствования. 


\section{ヘитература}

1. Вайндорф-Сысоева Марина Ефимовна. Методика дистанционного обучения: Учебное пособие для вузов. 2017.

2. Гречушкина Н. В., Нина Мартишина. Педагогическое общение в электронной информационно-образовательной среде. 2020.

3. Журавлева Ольга Борисовна, Борис Иванович Крук. Использование видео в дистанционном обучении. Для преподавателей и учителей. Издание второе. 2017.

4. Крук Б. И., О. Б. Журавлева, Е. Г. Струкова. Избранные главы теории и практики дистанционного обучения. 2017.

5. Мерецков Олег Вадимович. Создание электронного курса своими руками. 2019. 